\title{
Investigating mental health in patients with osteoarthritis and its relationship with some clinical and demographic factors
}

\author{
Masoumeh Nazarinasab ${ }^{1}$, Azim Motamedfar ${ }^{2}$, Azin Eskandari Moqadam ${ }^{3}$ \\ ${ }^{1}$ Department of Psychiatry, Golestan Hospital, Ahvaz Jundishapur University of Medical Sciences, Ahvaz, Iran \\ ${ }^{2}$ Department of Radiology, Golestan Hospital, Ahvaz Jundishapur University of Medical Sciences, Ahvaz, Iran \\ ${ }^{3}$ Student Research Committee, Ahvaz Jundishapur University of Medical Sciences, Ahvaz, Iran
}

\begin{abstract}
Objective: The reduction in the level of mental health, particularly depression is associated with outcome of treatment in patients with osteoarthritis (OA). There is no broader research into mental health or mental health care for OA patients. The purpose of the present study was to determine mental health and its relationship with some clinical and demographic factors among patients with $\mathrm{OA}$.

Material and methods: 94 patients with osteoarthritis were included in presented study. Patients were referred to hospital during the year of 2016, 30 male patients (31.9\%) and 64 female (68.1\%), female/male ratio was about $2: 1$. All patients were evaluated in the term of mental health through demographic questionnaire and SCL-90R questionnaire and the obtained data were analyzed using version 22 of SPSS Software.

Results: The results showed that $58.5 \%$ of patients with osteoarthritis had mental health disorders. Among all studied patients mental health disorders were found in 55 patients (58.5\%), including both isolated and complex disorders such as: psychological discomfort in the form of somatic symptoms disorder $(n=45)$, obsessive compulsive disorders $(n=43)$, interpersonal sensitivity $(n=44)$, depression ( $n=47)$, anxiety $(n=41)$, aggression $(n=52)$, phobia $(n=42)$, paranoid psychosis $(n=32)$, psychosis $(n=3)$. In addition, the prevalence of mental health problems in patients with OA was significantly higher at the age range of 18 to 20 years old $(p=0.002)$. Also revealed that the greater risk of mental health disorders is in the first months of diagnosis of OA compare to the patients with longer disease duration more than six months $(p=0.01)$ and patients taking corticosteroids were significantly higher risk of mental health disorders development $(p=0.00)$.

Conclusion: In presented study although the prevalence of OA is higher in group of older people, but psychiatric disorders is more common in OA patients with age range below 20 years. In addition, patients in the early months of OA are at greater risk of psychiatric disorders which the disorders were observed higher in patients taking corticosteroids.
\end{abstract}

Key words: osteoarthritis, mental health, SCL-90R questionnaire.

\section{Introduction}

Rheumatic diseases involving joints in some cases cause movement limitations and are responsible for some mental disorders and regardless of age. Among these diseases, osteoarthritis is the most common. Osteoarthritis (OA) causes that, due to pain, limitation of movement and non-inflammatory deformity of the joints daily activities are limited and OA may result in impairment of social function and may develop mental disorders of the patient [1]. Osteoarthritis is characterized by structural and functional changes in the joints $[2,3]$. Osteoarthritis is the most common type of arthri-

Address for correspondence:

Masoumeh Nazarinasab, Department of Psychiatry, Golestan Hospital, Ahvaz Jundishapur University of Medical Sciences, 6135733118

Ahvaz, Iran, e-mail: drnazarinasabm@gmail.com

Submitted: 13.05.2017; Accepted: 13.08.2017 
tis which effects on hands, knee, hip, spine, but may affect any joint and cause joint deformity, chronic disability and is the cause of replacement of the joint to the endoprosthesis [4].

Osteoarthritis is the major cause of disability and reduced quality of life, especially increases with age $[5,6]$. About one-third of people with the age of over than 65 years old experience symptomatic knee OA and about $18 \%$ of patients over 70 years old experience degenerative joint disease [7]. Prevalence of OA in women over 55 years of age for men is 12 to 1 [8]. It has been proven that the level of disability is associated with mental health and its most important dimension is mood and spirit of the patient [9]. Depression is the most common mood disorders which involves $12 \%$ of men and 10 to $25 \%$ of women. The prevalence of depression become higher with the existence of a chronic disease and its incidence varies between 20 and $25 \%$ in whole of the population $[10,11]$. Osteoarthritis is one of the main chronic joint diseases, in which depression has proven that the prevalence of depression is higher than general population [12].

The World Health Organization has defined mental health as harmonious relationship with others, the reform of personal and social environment and conflict resolution and personal problems in a logical and fair form [13]. Reduction in the level of mental health, particularly depression is associated with poor outcome in treatment on $\mathrm{OA}$ and often is a stronger forecaster of disability in patients with joint degenerative arthritis of knee or hip compare to the radiographic evidence $[14,15]$. The International Committee of Nutrition and Health (NHANES) showed that $49 \%$ of white women with knee OA have low and very low morale compare to women without knee pain. The next investigations of the Committee showed that the level of mental health has an inverse correlation with knee pain (independent of radiographic changes) $[16,17]$.

It has been previously proven that depression and disability in patients with rheumatoid arthritis (RA) have a close relationship with each other and each of the considered as a risk to other one. These findings pose question whether deterioration of function and disability in patients with $\mathrm{OA}$ are a risk factors for worsening mental status? But on the other hand, whether reduction in mental health level of patients with OA causes to more deterioration of function and disability? Due to high prevalence of mood disorders in patients with OA and their interference in the treatment process, it is recommended to take into account psychiatric evaluations in this group of patients [18]. Due to the shortage or even lack of studies has ever been conducted on mental health in patients with OA, as well as the importance of mental health care in the treatment procedure of OA patients the purpose of present study was to determine mental health in patients with OA and its relationship with some clinical and demographic factors.

\section{Material and methods}

The study was conducted on 94 patients diagnosed with osteoarthritis $(\mathrm{OA})$ in mean age $43.71 \pm 44$, In the whole study group were included 64 woman (68.1\%) and 30 men (31.9\%). Among them, 56 (85.7\%) patients were taking corticosteroids (GS) and 38 (18.4\%) were not treated with GS. In addition, the disease duration of 80 investigated patients (63.8\%) was lower than 6 month and only 14 (28.6\%) of them suffered from OA for more than six months. Also the patients were divided depending on three age bracket, education, marital status and affected joints. The collected data was presented in Table I.

After obtaining permission from the Ethics Committee of the Medical University of Joundi Shapor of Ahvaz, study was conducted with the aim of investigating mental health in OA patients referred to Golestan hospital of Ahvaz and its relationship with demographic and clinical variables. The patients after explaining the purpose of the study signed a form of informed consent.

Patients fulfilled two-part questionnaire including demographic characteristics (age, gender, marital status, income (patients with earn more than 300 USD

Table I. Characteristic of studied group

\begin{tabular}{|c|c|c|c|c|c|c|c|c|}
\hline Parameter & $\mathrm{N}$ & Mean & SD & Median & Min. & Max. & Q-1 & Q-3 \\
\hline \multicolumn{9}{|l|}{ Female $(n=64)$} \\
\hline age & 64 & 43.44 & 14.70 & 42.75 & 18 & 72 & 30 & 53.75 \\
\hline Time since OA diagnosis* & 64 & 4.05 & 2.34 & 3.63 & 1 & 11 & 2.00 & 6.00 \\
\hline \multicolumn{9}{|l|}{ Men $(n=30)$} \\
\hline age & 30 & 44.30 & 16.31 & 46.67 & 19 & 79 & 28.75 & 53.00 \\
\hline Time since OA diagnosis* & 30 & 4.00 & 3.12 & 2.75 & 1 & 10 & 1.75 & 6.50 \\
\hline
\end{tabular}

*Time of diagnosis - is expressed in months period from diagnosis to the time of the research 
per months as higher income and lower 33 USD as lower income etc.) and Symptom Checklist-90-Revised (SCL-90-R). The questionnaire includes 90 questions to assess psychiatric symptoms, which are reported by respondents. It was designed for a first time to show psychological aspects of physical and mental status of the patient. According to the study conducted by Taheri et al. on comprising mental health of patients with irritable bowel syndrome, the validity and reliability of Persian version of SCL-90R have been evaluated for several times, in which nine concurrent validity coefficients of the test were varied at the range between 0.36 to 0.73 and its estimated reliability coefficients using Cranach's alpha varied at the range between 0.77 to 0.90 [19]. It should be also noted that each of the questions of the test compose a range of 5 degrees of discomfort score from zero to 4 points (strong). The questions of the test involve 9 different dimensions ( 1 - somatization disorder, 2 - obsession and compulsion, 3 - interpersonal sensitivity, 4 - depression, 5 - anxiety, 6 - aggression, 7 - disease phobia, 8 - paranoid thoughts and 9 - psychosis). Finally, data were described through mean and standard deviation in quantitative variables and frequency in qualitative variables. Chi-square test was also used to data analysis. All of the analyses were carried out using version 22 of SPSS Software.

\section{Results}

Generally 55 patients (58.5\%) presented mental health problems based on the SCL-90R questionnaire. The data were also analyzed with the separation of un-

Table II. Mental status sort by patients characterizations

\begin{tabular}{|c|c|c|c|c|}
\hline \multirow[t]{2}{*}{ Variable } & \multirow[t]{2}{*}{ Indicators } & \multicolumn{2}{|c|}{$\begin{array}{l}\text { Percent of patients } \\
\text { from each subgroup (\%) }\end{array}$} & \multirow[t]{2}{*}{$P$-value } \\
\hline & & $\begin{array}{l}\text { Confirmed mental } \\
\text { health disorder }\end{array}$ & Healthy & \\
\hline \multirow[t]{3}{*}{ Age } & $18-20(n=6)$ & 83.3 & 16.7 & \multirow{3}{*}{0.00} \\
\hline & $21-40(n=36)$ & 77.8 & 22.2 & \\
\hline & $41-60(n=52)$ & 42.3 & 57.7 & \\
\hline \multirow[t]{2}{*}{ Gender } & Male $(n=30)$ & 60.0 & 40.0 & \multirow[t]{2}{*}{0.84} \\
\hline & Female $(n=64)$ & 57.8 & 42.2 & \\
\hline \multirow[t]{2}{*}{ Duration of the OA } & Under 6 months $(n=80)$ & 63.8 & 36.3 & \multirow[b]{2}{*}{0.01} \\
\hline & More than 6 months $(n=14)$ & 28.6 & 71.4 & \\
\hline \multirow[t]{2}{*}{ Marital Status } & Married $(n=79)$ & 54.4 & 45.6 & \multirow[t]{2}{*}{0.06} \\
\hline & Single $(n=15)$ & 80.0 & 20.0 & \\
\hline \multirow[t]{2}{*}{ Glucocorticosteroids } & Use $(n=56)$ & 85.7 & 14.3 & \multirow[t]{2}{*}{0.00} \\
\hline & Not use $(n=38)$ & 18.4 & 81.6 & \\
\hline \multirow[t]{2}{*}{ Income } & Low income $(n=81)$ & 56.8 & 43.2 & \multirow{2}{*}{0.39} \\
\hline & Highest income $(n=13)$ & 69.2 & 30.8 & \\
\hline \multirow[t]{5}{*}{ Education } & Illiterate $(n=40)$ & 47.5 & 52.5 & \multirow{5}{*}{0.1} \\
\hline & Diploma $(n=18)$ & 61.1 & 38.9 & \\
\hline & Associate degree $(n=15)$ & 53.3 & 46.7 & \\
\hline & Bachelor $(n=19)$ & 84.2 & 15.8 & \\
\hline & Master degree $(n=2)$ & 50.0 & 50.0 & \\
\hline \multirow[t]{8}{*}{ Affected joint } & Hand, foot and knee $(n=1)$ & 0.00 & 100.0 & \multirow{8}{*}{0.00} \\
\hline & Hand $(n=5)$ & 40.0 & 60.0 & \\
\hline & Hand, foot and neck $(n=1)$ & 100.0 & 0.00 & \\
\hline & Hip and leg $(n=3)$ & 0.00 & 100.0 & \\
\hline & $\operatorname{Neck}(n=11)$ & 45.5 & 54.5 & \\
\hline & Knee $(n=1)$ & 100.0 & 0.99 & \\
\hline & Hand and neck $(n=21)$ & 9.5 & 90.5 & \\
\hline & More than 4 joints $(n=51)$ & 86.3 & 13.7 & \\
\hline
\end{tabular}




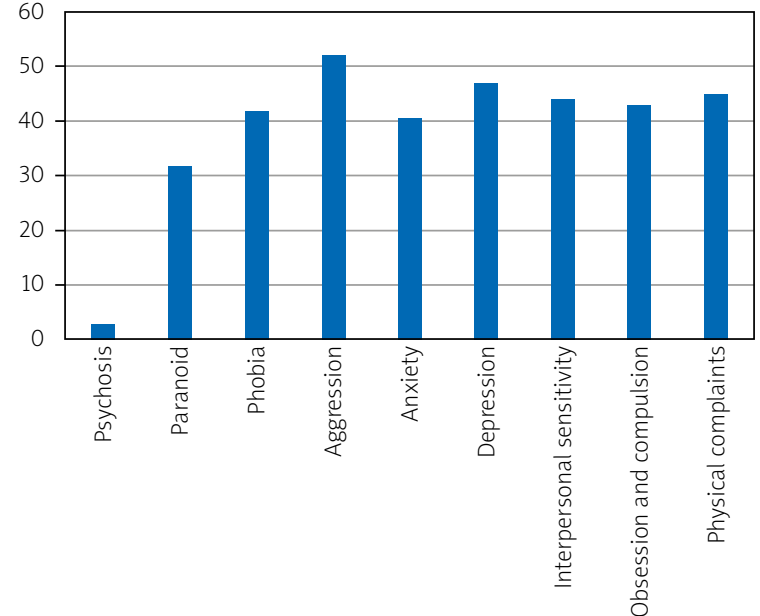

Fig. 1. Evaluation of nine dimensions of questionnaire

der study variables. According to the SCL-90R mental health questionnaire, in group with recognized mental health disorders $-83.3 \%(n=5)$ patients were at age range of 18 to 20 years, $28.8 \%(n=28)$ patients were at age range of 21 to 40 years old and $42.3 \%(n=22)$ patients with metal health disorder were at age range of 41 to 60 . There was a statistical significant difference between age group $(p=0.002)$. The prevalence of mental health disorders was higher in patients with OA at the younger age $(p=0.00)$. There was no statistically significant difference $(p=0.84)$ according to gender. The duration of the mental disorder was different; there were a 51 patients with a history of disease under 6 months and 4 patients with a history of disease older than 6 months. The prevalence of mental health disorders was significantly higher in patients with a history of $\mathrm{OA}$ under 6 months $(p=0.01)$. Also 48 patients treated with glucocorticoids and 7 untreated suffered from mental health disorders, and the prevalence of mental health disorders in glucocorticosteroids group was significantly higher $(p=0.00)$. Marital status of the patients studied had no significant impact on the development of mental disorders $(p=0.06)$. There was no statistically significant difference between patients with lower income $(n=46)$ and patients with higher $(n=9 ; p=0.39)$. As well as there was no statistical significant differences between well-educated patients and worse educated $(p=0.11)$. This result is summarized in Table II. The prevalence of mental health disorders was significantly lower in patients with hip and peripheral joint involvement of lower limbs $(p=0.00)$. In continue of the study, nine dimensions of the questionnaire were investigated which the results showed that among total 94 studied patients 55 patients presented mental health disorders which occurred both isolated and complex disorders such as: psychological discomfort in the form of somatic symptoms disorder $(n=45)$, obsessive compulsive disorders $(n=43)$, interpersonal sensitivity $(n=44)$, depression $(n=47)$, anxiety $(n=41)$, aggression $(n=52)$, phobia $(n=42)$, paranoid psychosis $(n=32)$, psychosis $(n=3)$ which was presented in figure 1.

\section{Discussion}

The results of presented study showed that 58.5\% of patients with OA had mental health disorders. The prevalence of nine mental health disorders was high in them, and depression which had the highest level of prevalence than psychosis which had the lowest level of prevalence in OA patients.

According to the results of present study, the prevalence of OA was lower at age of 18 to 20 and hence lower number of patients were investigated in this age range in the term of mental health disorders, but the prevalence of mental health disorders in younger group was higher compare to the patients of other age ranges. In continue, it was observed that the prevalence of mental health disorder was higher in OA patients with disease duration lower than 6 months which can be due to the short term dealing of patient with the disease and intolerant patients in the short time and the patient need to more time to achieve a stable mental condition. It was also observed that the prevalence of mental health disorder was higher in patients taking glucocorticosteroids what would require further research. Finally, it was observed that the prevalence of mental health problems had a large distribution in people with different affected joints. This fact should be considered when analyzing patient functional limitations.

The results of present study showed the prevalence of mental health disorders in OA patients with the separation of several variables. But the next step in recognizing patients of under study population was to comprise the results of present study with the results of similar studies. Hence in continue, similar studies have been reviewed and their results have been comprised with the results of present study. Firstly, the investigation history of OA patients in this geographical area which conducted by Nasab et al. [20] in 2009 in Jondi Shapour University of Medical Sciences with the aim of evaluating prevalence of risk factors in primary OA of the knee was reviewed. The cross-sectional and prospective study was conducted on general population referred to orthopaedic clinic of Razi Hospital during a year. In this study indicators such as age, gender, weight, and occupation were investigated. The group of $400 \mathrm{OA}$ patients were detected as qualify to participate into the study. In this study 69\% patients were 60 years of age or older. Also in described research, obe- 
sity, female gender, age over 60 years were the favorable factors of patients with OA [20].

In our study, the highest number of patients was younger in age between 41 to 60 years old $(n=52$; $55.3 \%$ ). But similar to their study, prevalence of the OA was higher in women compare to men. Nasab et al. [20] also took into account, which joints were involved in $\mathrm{OA}$ Many studies have been conducted on the prevalence of mental health problems in patients with arthritis not only OA as: Matcham et al. [21] conducted a randomized clinical trial study on 379 patients with rheumatoid arthritis and investigated the relationship between depression and anxiety and physical symptoms in patients with arthritis. According to their study, symptoms of depression and anxiety are associated with disability and joint pain and reduce response to treatment [21].

Other study was conducted by Dave et al. [22] on 267 patients with OA of the knee. In this study $63 \%$ of the patients were women with age range of 66 years and $37 \%$ of them were men with age range of 68 years. After adjusting and analyzing factors such as age and gender, researchers found that there is a relationship between the number of painful joints, stiff joints in the morning and disability with pain threshold and mental health ( $p$ $<0.05$ ). The study recommended that early diagnosis and treatment of mood disorders such as anxiety and depression disorders would improve the mental health of people with OA as well as may improve their treatment response due to the high prevalence of such disorders in patients with OA [22]. In present study, anxiety and depression had the highest level of prevalence as like their conclusion. Abbasi et al. [23] conducted a study in Qazvin University of Medical Sciences to determine the relationship between anxiety and depression with osteoarthritis. This study was conducted on 100 patients with OA and100 healthy volunteers. In this study, $66 \%$ of OA patients and $58 \%$ of control group were diagnosed with depression, which was not a statistically significant difference. However chronic diseases such as OA cause an increase in anxiety and depression and may have negative influence on mental health of patients [23]. Although the patients of control group were not considered in present study, common and similar results from both studies is the high prevalence of depression among patients with $\mathrm{OA}$.

\section{Conclusions}

Results obtained from present study and reviewing the results of similar studies showed that although the prevalence of OA is higher in older people, but the prevalence of mental health disorders is higher in patients with OA at the younger age. In addition, patients are at greater risk of mental health disorders in the first months of diagnosis of OA and its level is higher in patients treated with glucocorticosteroids. In addition, there was a frequency distribution in the prevalence of mental health disorders in OA patients depending on affected joints, hence it is recommended to conduct a comprehensive study by taking into account a location of involved joints.

The authors declare no conflict of interest.

\section{References}

1. Verbrugge LM, Gates DM, Ike RW. Risk factor for disability among US adults with arthritis. J Clin Epidemiol 2013; 44: 167-182.

2. Cushnagham J, Dieppe P. Study of 500 patients with limb joint osteoarthritis I: Analysis by age, sex, and distribution of symptomatic joint sites. Ann Rheum Dis 2013, 50: 8-13.

3. Van Bear MT, Dekker J, Lemens JAM, et al. Pain and disability in patient with OA of hip and knee. The relationship with articular, kinesiological and psychological characteristic. J Rheumatol 2010; 25: 125-133.

4. Altman R, Asch E, Bloch D, et al. Development of criteria for the classification and reporting of osteoarthritis. Classification of osteoarthritis of the knee. Diagnosis and Therapeutic Criteria Committee of the American Rheumatism Association. Arthritis Rheum 2012; 29: 1039-1049.

5. Creamer P, Lethbridge-Cejku M, Costa P, et al. The relationship of anxiety and depression with self-reported knee pain in the community: data from the Baltimore Longitudinal Study of Aging. Arthritis Care Res 2014; 12: 3-7.

6. Hochberg MC, Lawrence RC, Everett DF, Cornoni-Huntley J. Epidemiologic associations of pain in osteoarthritis of the knee: data from the National Health and Nutrition Examination Survey and the National Health and Nutrition Examination-1 Epidemiologic Follow-up Survey. Semin Arthritis Rheum 2013; 18 (Suppl 2): 4-9.

7. Lwata M, Ota KT, Duman RS. The inflammasom: pathways linking psychological stress, depression, and systemic illnesses. Brain Behav Immun 2013; 31: 105-114.

8. Felson DT, Naimark A, Anderson J, et al. The prevalence of knee osteoarthritis in the elderly. The Framingham Osteoarthritis Study. Arthritis Rheum 2012; 30: 91-98.

9. Hopman-Rock M, Odding E, Hofman A, et al. Physical and psychological disability in eilderly subjects in relation to pain Hip and/or knee. J Rheumatol 2013; 23; 1037-1044.

10. Wright GE, Parker JC, Smarr KL, et al. Age, depressive symptoms and RA. Arthritis Rheum 2013; 41: 298-305.

11. American Psychiatric Association. Diagnostic and statistical Manual of Mental disorders $4^{\text {th }}$ ed. Mosby Co, Washington DC, USA 2011; 317-393.

12. Sadock's Comperhensive textbook of psychiatry, 7th ed. Lippincott Williams \& Wilkins Co, Philadelphia USA 2014; 12981377. 
13. Dave D, Rashad I, Spasojevic J. The effects of retirement on physical and mental health outcomes. National Bureau of Economic Research 2015; 29: 47-60.

14. Sheehy C, Murphy E, Barry M. Depression in rheumatoid arthritis underscoring the problem. Rheumatology (Oxford) 2014 45: 1325-1327.

15. Ang DC, Choi H, Kroenke K, Wolfe F. Comorbid depression is an independent risk factor for mortality in patients with rheumatoid arthritis. J Rheumatol 2015; 32: 1013-1019.

16. Freeling P, Rao BM, Paykel ES, et al. Unrecognised depression in general practice. Br Med J (Clin Res Ed) 1985; 290: 1880-1883.

17. Atapour J, Shakibi MR, Rajabizadeh GH, Saroteh-Rigi M. The reletionship between depression and disability in patient with rheumatoid arthritis in Kerman. Journal of Kerman University of Medical Sciences 2002; 92: 79-85.

18. Katon W, Lin E, Von Korff M, et al. The interface between physical and psychological symptoms. Prim Crim Care Companion J Clin Psychiatr 2013; 5 (Suppl 7): 11-18.

19. Nazarinasab M, Pakseresht S, Fadai M. Investigating the mental health status of patients with ulcerative colitis and its relationship with clinical and demographic variables. Int J Pharma Res Health Sci 2017; 5: 1632-1636.

20. Mehdi Nasab SA, Haddadpoor AA, Sarrafan N, et al. Prevalence and evaluation of risk factors in primary knee osteoarthritis. Scientific Medical Journal (AJUMS) 2010; 9: 135-141.

21. Matcham F, Norton S, Scott D, et al. Symptoms of depression and anxiety predict treatment response and long-term physical health outcomes in rheumatoid arthritis: secondary analysis of a randomized controlled trial. Rheumatology (Oxford) 2015; 8: 306-338.

22. Dave AJ, Selzer F, Losina E, et al. Is there an association between whole-body pain with osteoarthritis-related knee pain, pain catastrophizing, and mental health? Orthop Related Res 2015; 473: 3894-3902.

23. Abbasi M, Yazdi Z, Farrokh Z, Haji Seid Javadi S. Association of depression and anxiety with osteoarthritis. J Qazvin Univ Med Sci 2014; 18: 28-34. 